\title{
Analysis of the Effect of Anode Porosity on Temperature Distribution on Planar Radial Type SOFC
}

\author{
Alif Widiyanto $^{1, *}$, Sulistyo $^{1,2}$, and MSK Tony Suryo Utomo ${ }^{1,2}$ \\ ${ }^{1}$ Magister Program of Energy, School of Postgraduate Studies, Diponegoro University, Semarang - Indonesia \\ ${ }^{2}$ Department of Mechanical Engineering, Faculty of Engineering, Diponegoro University, Semarang - Indonesia
}

\begin{abstract}
Solid Oxide Fuel Cell (SOFC) is an electrochemical equipment that converts gas into electricity directly. The waste products resulting from SOFC are water vapor and heat when using hydrogen gas. The electrode of the SOFC is the anode, electrolyte and cathode. The performance of SOFC is influenced porosity of the electrode. This study explained the relationship between porosity of the anode and temperature distribution using computational fluid dynamics modeling approach (CFD). In this study, CFD modeling was done by using Fluent software. The geometry model of computational modeling is a planar radial-type SOFC. The assumptions of some boundary conditions used from the study of literature and the object of study. The standard deviation and the different of temperature of the anode-electrolyte surface used to analyse the result. Non-homogenous temperature distribution rise if the anode porosity and gas flow rate is increasing. This indicates the gradient of temperature is bigger in the higher porosity, which may cause thermal stress and degrades the materials of electrode.
\end{abstract}

Keywords: SOFC; anode; porosity; temperature.

\section{Introduction}

Solid Oxide Fuel Cell (SOFC) is a device that converts fuel and oxygen directly into electrical energy [1]. SOFC technology development is very important to support low emission policies such as EURO 4 and Environmental Protecton Agency (EPA) policies, because the emissions produced by SOFC are zero when using hydrogen fuel, eventhough SOFC fuel is not limited to hydrogen but other fuels can be used like methane, ethanol, and many others hydrocarbon fuels.

Solid Oxide Fuel cell is a very environmentally friendly energy convertion. The principle of fuel cell work is based on an electrochemical process that produce the heat and water vapor when using hydrogen fuel, where the water vapor is very enviromentally friendly [1].

There are several type of fuel cell. One type of fuel cell that use the ceramic material is Solid Oxide Fuel Cell (SOFC). Solid Oxide Fuel Cell (SOFC) is one of several types of fuel cell technology operating at temperatures between $600^{\circ} \mathrm{C}-1000^{\circ} \mathrm{C}$ [2] and developed for the use of power station systems and vehicle [3].

SOFC performance is affected by the quality of the anode. The SOFC anode component must have porosity to perform its function [4].The SOFC anode serves as a transport medium and hydrogen gas oxidation process. The anode also acts as a catalyst in the electrochemical process occurring within the SOFC system. The famous of SOFC anode material is NiO / YSZ (Nickel Oxide / Yttria Stabilized Zirconia) [5].
The SOFC anode porosity will form an area that was called the three phase boundary (TPB). Electrical energy can be generated by SOFC from the electrochemical reaction occurring in the TPB area [6]. The SOFC anode must have a large size of TPB to facilitate the electrochemical reaction that can produce more electron in the process. The higher porosity will increase the number of TPB [5] [7]. The porosity can also affect a conductivity and a strength of the anode [7]. To facilitate mass transfer anodes typically have porosities ranges from 0,2 to 0,4 [5].

Figure 1 show an illustration of the basic SOFC scheme. The main component of SOFC consists of electrodes, that is anode, electrolyte and cathode.

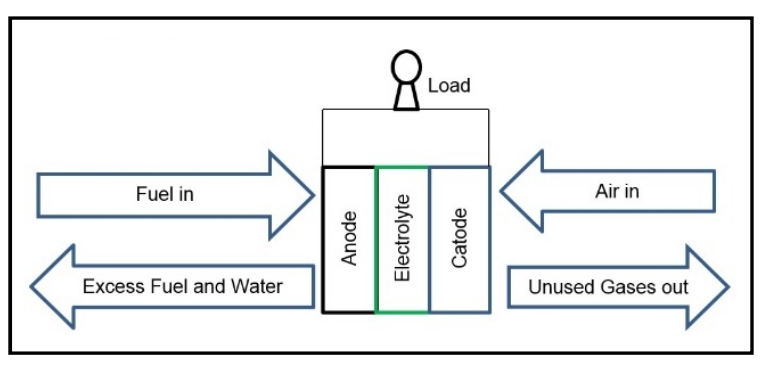

Fig.1. The basic Solid Oxide Fuel Cell scheme.

The reaction of the fuel in the SOFC are:

- Basic reaction processes at the anode

$\mathrm{H}_{2} \longrightarrow 2 \mathrm{H}^{+}+2 \mathrm{e}^{-}$

- Reaction processes at the cathode $1 / 2 \mathrm{O}_{2}+2 \mathrm{H}^{+}+2 \mathrm{e}^{-} \longrightarrow \mathrm{H}_{2} \mathrm{O}$

* Corresponding author: alifundip@gmail.com 
- Over all reaction

$$
\mathrm{H}_{2}+1 / 2 \mathrm{O}_{2} \longrightarrow \mathrm{H}_{2} \mathrm{O}
$$

Currently, the challenges of the develop SOFC is minimize non-homogenous temperatur distribution, which cause the thermal strees. The thermal stress which can degrades the material of electrode, so the performance of SOFC will decrease. The purpose of this study is to know which porosity value has the smallest gradient temperature which can be reduce thermal stress in this SOFC model, although the thermal stress distribution was not study.

\section{Methodology of study}

\subsection{Flow chart of study}

The flow chart used for this study is shown in Figure 2 below.

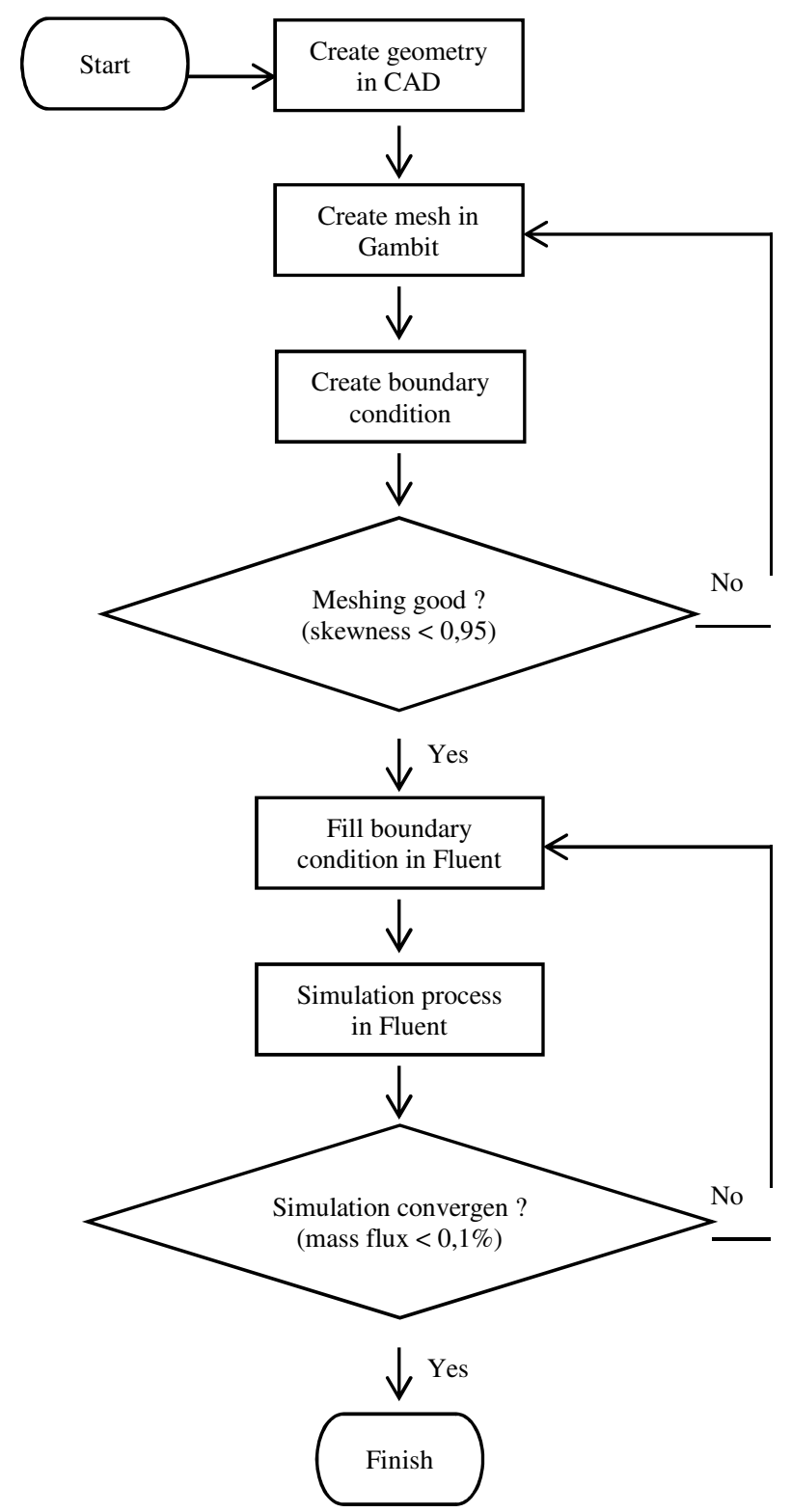

Fig. 2. Computational flowchart methods.

\subsection{SOFC modeling}

Geometry model is used to solve the problems. It was simulated based on fluid dynamics computational method (CFD) using Fluent software as processor and postprocessor. Figure 3 shows the geometry model used in this study. The model of geometry was planar radial-type SOFC. The geometry model was used as the first study object that it was observed and will be carried out in the direct measurement.

The computational methods of the simulation process can be explained through the flowchart diagram in Figure 2. The computation process begins using the creation of geometry with the appropriate size of the object. The mesh-making and the determination of boundary conditions are performed by using geometry model. The results of CFD Fluent simulation process is influenced by the meshing process and the determination of boundary conditions. The next computing process is called a processing and a post processing. The post processing data will be used as the basis of analysis of the study after the simulation reach convergent.

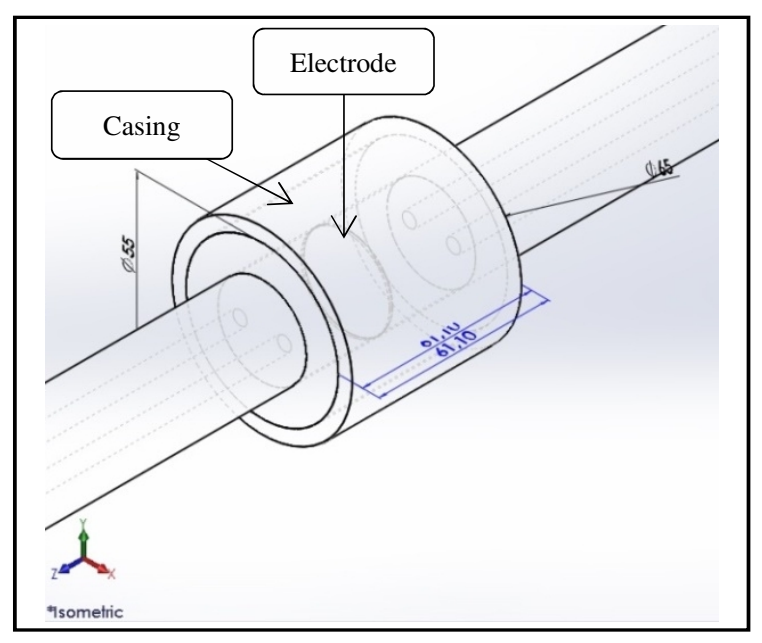

Fig. 3. Geometry model.

\subsection{Basic equation}

The problem will be solve using Fluent SOFC addon module. The fluent is one of the CFD software that is able to simulate fluid flow phenomena, conduction and convection heat transfer [4] [8]. CFD Fluent solves the solution of thermodynamic fluid problems with volume adjusting techniques related to the continuity, momentum, and energy equations [8].

The study explained the relationship between anode porosity and temperature distribution. The equilibrium of porous media was assumed that there is no temperature difference between the fluid phase and solid phase and it can be written as follows [6] [9]:

- Continuity equation:

$$
\frac{\partial U}{\partial x}+\frac{\partial V}{\partial y}+\frac{\partial W}{\partial z}=0
$$

where $U, V$ and $W$ is velocity components, $x y$ and $z$ is spatial coordinates [6]. 
- The mass transfer equation:

$$
\begin{gathered}
\varepsilon \frac{\partial w}{\partial t}+\left[U \frac{\partial w}{\partial x}+V \frac{\partial w}{\partial y}\right]= \\
D\left(\frac{\partial^{2} w}{\partial x^{2}}+\frac{\partial^{2} w}{\partial y^{2}}\right)-(1-\varepsilon) \frac{\rho_{s}}{\rho_{f}} \frac{\partial \bar{C}}{\partial t}
\end{gathered}
$$

where $\varepsilon$ is porosity, $w$ is absolute humidity, $t$ is time, $x$ and $y$ is spatial coordinates, $D$ is diffusion coefficient, $\rho_{s}$ is mass density solid phase, $\rho_{f}$ is mass density fluid phase, $\bar{C}$ is mean value of the moisture content [6].

- Momentum equation (Darcy's Law):

$$
U=-\frac{K}{\mu} \frac{\partial p}{\partial x} \text { and } V=-\frac{K}{\mu} \frac{\partial p}{\partial y}
$$

where $U$ and $V$ is velocity component, $K$ is permeability, $\mu$ is dynamic viscosity, $p$ is pressure, $x$ and $y$ is spatial coordinates [6].

- Energy equation:

$$
\begin{gathered}
\overline{\mathrm{V}}\left(\vec{v}\left(\sum_{i} Y_{i} h_{i}+p\right)\right)= \\
\overline{\mathrm{V}}\left(k_{e f f} \overline{\mathrm{V}} T+\sum_{i} h_{i}\left(\sum_{j=1}^{n-1} \rho D_{i j} \overline{\mathrm{V}} Y_{j}\right)\right)+S_{h}
\end{gathered}
$$

The porous medium is an anode electrode with a certain porosity, so $k_{\text {eff }}$ can be calculated by the following equation:

$$
\begin{array}{r}
(\rho \mathrm{Cp})_{\mathrm{eff}}=\varepsilon(\rho \mathrm{Cp})_{\mathrm{f}}+(1-\varepsilon)(\rho \mathrm{Cp})_{\mathrm{s}} \\
k_{\text {eff }}=\varepsilon k_{f}+(1-\varepsilon) k_{s}
\end{array}
$$

where $\varepsilon$ is the porosity of the porous medium, $k_{\text {eff }}$ is the effective thermal conductivity of the medium, $k_{f}$ is the thermal conductivity of fluid phase, $k_{s}$ is the thermal conductivity of solid phase [9].

\subsection{Boundary condition and assumptions}

The SOFC anode is assumed to be an isotropic and homogeneous porous medium. The gas fluid is assumed to be incompressible with laminar flow due to its low velocity and pressure [8] [10].

Fluent computational modeling use an ideal mixture gas at the inlet side of the cell with $27^{\circ} \mathrm{C}$. Heating equipment is a homogeneous source of heat. The assumption of heat transfer in the porous anode occured by conduction, while the electrochemical reactions, convection heat transfer and radiation were ignored. The simulation was performed by on three-dimensional geometric anode model. The model used a radial planar geometry which the size was made according to the object of study. Modeling uses several assumptions of boundary conditions derived from a literature sources and an actual conditions. Modeling boundary conditions are mentioned in table 1 and table 2.

Table 1. Anode material

\begin{tabular}{|c|c|c|}
\hline Boundary condition & $\begin{array}{c}\text { Anode } \\
\text { (Ni/YSZ) }\end{array}$ & References \\
\hline Diameter $(\mathrm{mm})$ & 32 & $\begin{array}{c}\text { Based on material } \\
\text { specimen }\end{array}$ \\
\hline Thickness $(\mathrm{mm})$ & 0,8 & {$[5]$} \\
\hline Porosity & $0,2-0,4$ & {$[8]$} \\
\hline $\begin{array}{c}\text { Thermal conductivity } \\
\left(\mathrm{W} \mathrm{m}{ }^{-1} \mathrm{~K}^{-1}\right)\end{array}$ & 6 & \\
\hline Specific heat $\left(\mathrm{J} \mathrm{kg}^{-1} \mathrm{~K}^{-1}\right)$ & 600 & \\
\hline Density $\left(\mathrm{kg} \mathrm{m}^{-3}\right)$ & 7740 & \\
\hline Viscous resistance $\left(\mathrm{m}^{-2}\right)$ & $1,00 \times 10^{8}$ & \\
\hline
\end{tabular}

Table 2. Casing material

\begin{tabular}{|c|c|c|}
\hline Boundary condition & Alumina 94\% & Reference \\
\hline Thermal conductivity & 18 & \multirow{2}{*}{ [11] } \\
\hline Spesific heat $\left(\mathrm{J} \mathrm{kg}^{-1} \mathrm{~K}^{-1}\right)$ & 880 & \\
\hline Density $\left(\mathrm{kg} \mathrm{m}^{-3}\right)$ & $3,69 \times 10^{6}$ & \\
\hline Porosity & - & \\
\hline Thickness $(\mathrm{mm})$ & 6 & \\
\hline
\end{tabular}

\section{Results and discussion}

\subsection{Simulation result}

Computational method is done based on the principle of finite volume method. Fluent is the solver of the simulation. Assumptions have been established based on the literature and geometry sources from the study specimens. The geometry grid is shown in Figure 4.

The simulations in this study use boundary conditions: gas flow is assumed laminar, incompresible ideal gas. The gas velocity inlet is $1 \mathrm{~ms}^{-1}$ and $2 \mathrm{~ms}^{-1}$ [12], constant temperature of heating wall is $800^{\circ} \mathrm{C}$, simulation is done under steady state conditions. Verify the results of computing based on convergence criteria and flux report. The convergence criterion for continuity and fluid flow is $10^{-3}$, while for energy equation is $10^{-6}$ [13] [14].

Standard deviation data of temperature distribution was taken based on 20 points along the line A and B (see in Figure 4).

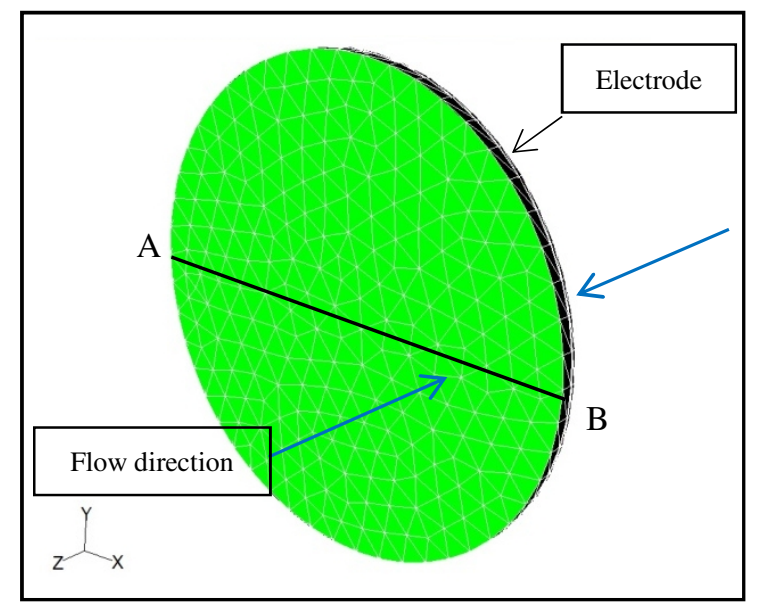

Fig. 4. Display grid. 
Based on Figure 5 shows contours of temperatur distribution at velocity inlet the gas is $1 \mathrm{~ms}^{-1}$. Maximum temperature at porosity 0,2 is $799,706^{\circ} \mathrm{C}$ and the minimum temperature is $792,106^{\circ} \mathrm{C}$. The different of temperatur $(\Delta \mathrm{T})$ is $7,6^{\circ} \mathrm{C}$.

Predicted temperature distribution at velocity inlet gas is $1 \mathrm{~ms}^{-1}$ when porosity is 0,3 shows in Figure 6. Minimum temperature is $791,647^{\circ} \mathrm{C}$ and the maximum temperature is $799,705^{\circ} \mathrm{C}$. The different of temperatur $(\Delta \mathrm{T})$ is $8,058^{\circ} \mathrm{C}$.

Based on Figure 7 shows contours of temperatur distribution at velocity inlet the gas is $1 \mathrm{~ms}^{-1}$ and the porosity of anode is 0,4. Maximum temperature is $799,702^{\circ} \mathrm{C}$ and the minimum temperature is $791,126^{\circ} \mathrm{C}$. The different of temperatur $(\Delta \mathrm{T})$ is $8,576^{\circ} \mathrm{C}$.

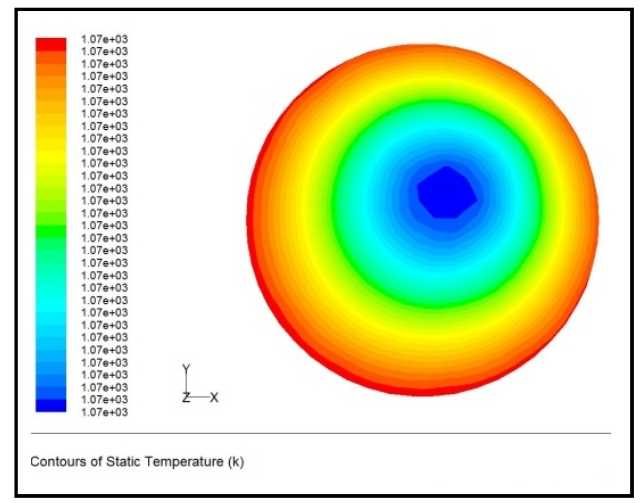

Fig. 5. Temperature contours effect of velocity inlet $1 \mathrm{~ms}^{-1}$ with anode porosity 0,2 .

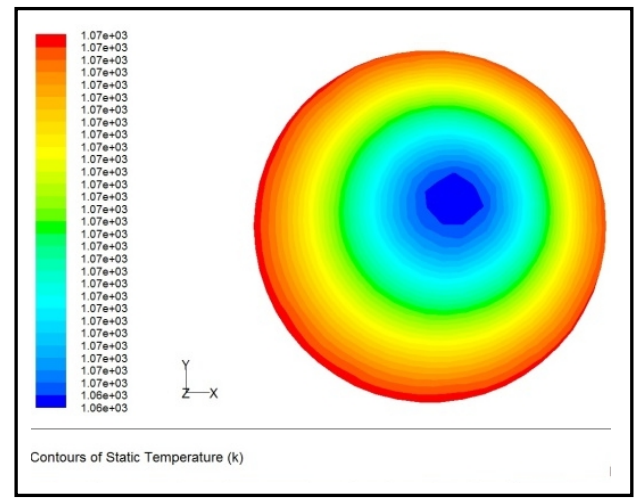

Fig. 6. Temperature contours effect of velocity inlet $1 \mathrm{~ms}^{-1}$ with anode porosity 0,3 .

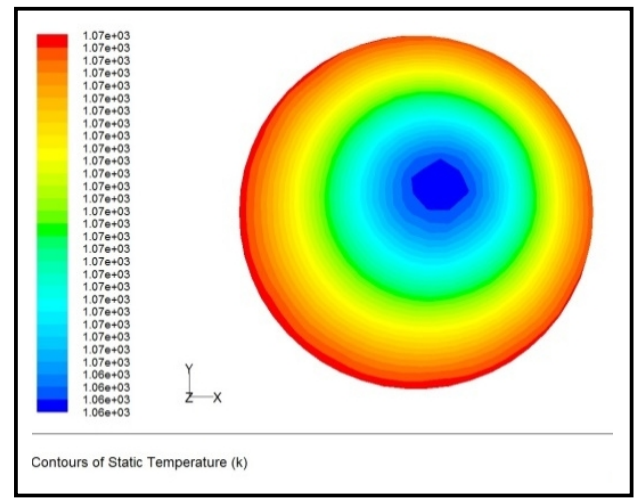

Fig. 7. Temperature contours effect of velocity inlet $1 \mathrm{~ms}^{-1}$ with anode porosity 0,4 .

Based on Figure 8 shows contours of temperatur distribution at gas flow inlet is $2 \mathrm{~ms}^{-1}$. Maximum temperature at porosity 0,2 is $798,885^{\circ} \mathrm{C}$ and the minimum temperature is $764,339^{\circ} \mathrm{C}$. The different of temperatur $(\Delta \mathrm{T})$ is $34,546^{\circ} \mathrm{C}$.

Predicted temperature distribution at gas flow inlet is $2 \mathrm{~ms}^{-1}$ when porosity is 0,3 shows in Figure 9. Minimum temperature is $762,524^{\circ} \mathrm{C}$ and the maximum temperature is $798,879^{\circ} \mathrm{C}$. The different of temperatur $(\Delta \mathrm{T})$ is $36,355^{\circ} \mathrm{C}$.

Based on Figure 10 shows contours of temperatur distribution at gas flow inlet is $2 \mathrm{~ms}^{-1}$ and the porosity of anode is 0,4 . Maximum temperature is $798,871^{\circ} \mathrm{C}$ and the minimum temperature is $760,467^{\circ} \mathrm{C}$. The different of temperatur $(\Delta \mathrm{T})$ is $38,404^{\circ} \mathrm{C}$.

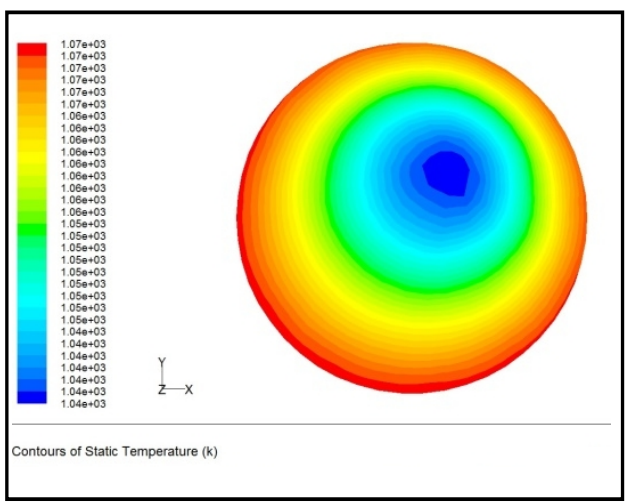

Fig. 8. Temperature contours effect of gas flow inlet $2 \mathrm{~ms}^{-1}$ with anode porosity 0,2 .

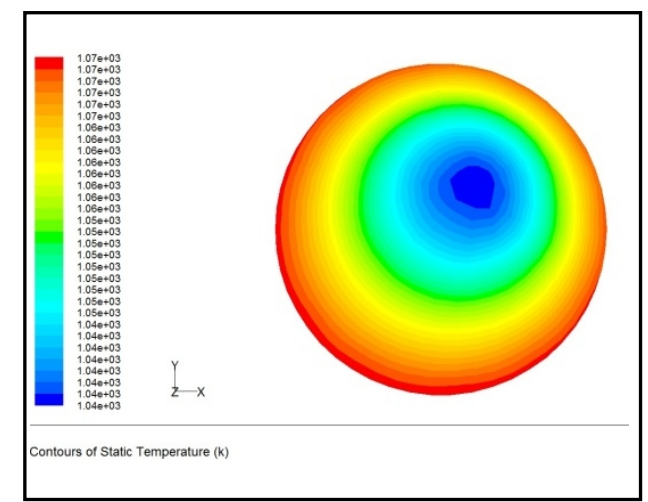

Fig. 9. Temperature contours effect of gas flow inlet $2 \mathrm{~ms}^{-1}$ with anode porosity 0,3 .

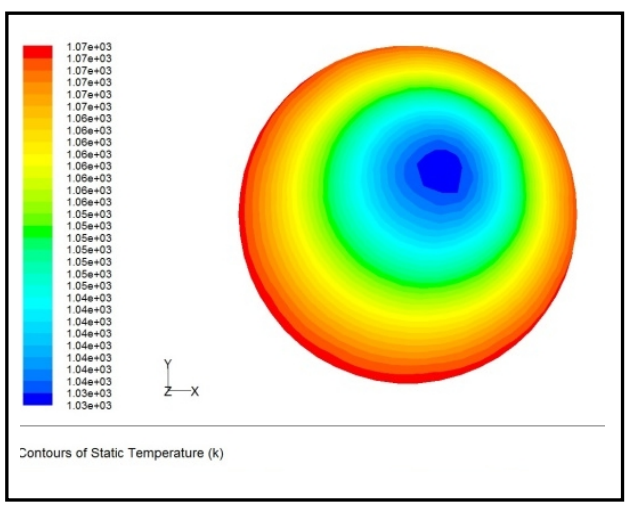


Fig. 10. Temperature contours effect of gas flow inlet $2 \mathrm{~ms}^{-1}$ with anode porosity 0,4 .

Table 3. Average Temperature and Standard Deviation

\begin{tabular}{|c|c|c|c|}
\hline $\begin{array}{c}\text { Boundary } \\
\text { Condition }\end{array}$ & $\begin{array}{c}\text { Anode } \\
\text { Porosity }\end{array}$ & $\begin{array}{c}\mathbf{T}_{\text {ave }} \text { at Anode- } \\
\text { Electrolyte } \\
\text { Surface } \mathbf{~}^{\circ} \mathbf{C} \text { ) }\end{array}$ & $\begin{array}{c}\text { Standard } \\
\text { Deviation }\end{array}$ \\
\hline \multirow{2}{*}{$\begin{array}{c}\text { Velocity inlet } \\
\text { gas } 1 \mathrm{~ms}^{-1}\end{array}$} & 0,2 & 795,33 & 2,46 \\
\cline { 2 - 4 } & 0,3 & 795,07 & 2,61 \\
\hline \multirow{2}{*}{$\begin{array}{c}\text { Velocity inlet } \\
\text { gas } 2 \mathrm{~ms}^{-1}\end{array}$} & 0,4 & 794,77 & 2,77 \\
\cline { 2 - 4 } & 0,2 & 779,96 & 10,32 \\
\hline
\end{tabular}

Standard deviation of temperatur is very important to calculate temperatur difference on the surface area. It can be used to investigated dispersion of the selected value from the average temperature of anode-electrolyte surface.

Average temperatur and standard deviation of temperatur was taken from anode and electrolyte surface. Based on Table 3 can be expressed that the lowest standard deviation is 0,2 porosity with gas flow rate $1 \mathrm{~ms}^{-}$ 1 , while the highest standard deviation value is 0,4 porosity with gas flow rate $2 \mathrm{~ms}^{-1}$.

\subsection{Simulation result analysis}

High porosity values can be increased TPB, also they can facilitate the gas transport more higher. However, high porosity will also rise the standard deviation of temperature.

Anode porosity will effects temperatur distribution but not significant, that shows the standard deviation of temperatur is very small. The rate of gas flow greatly effects the temperatur distribution. The higher rate of gas flow will have an impact on the increasing value of temperature gradient, this means that the rising gas flow rate will have a high impact on the possibility of thermal stress on the material. Degrades the materials of SOFC electrode rise when the standard deviation of temperatur increasing, so it is predicted that SOFC performance will also decrease.

\section{Conclusion}

The standard deviation of temperatur can be used to investigated the gradient temperature and predicted degrades the material electrode. Degrades the material electrode that indicate the SOFC performance will decrease. The anode porosity will affect the temperature distribution but not significant because the differences of standard deviation of temperatur is very small. Lower porosity of anode will reduce the number of TPB, and the lower porosity anode also affect the transport gas process. Higher porosity of anode will increase number of TPB but gradient temperature will increase too. The higher gas flow rate can be effect on the temperature distribution become non-homogenous.

\section{References}

1. Giorgi Leonardo, and Leccese Fabio, Fuel Cells: Technologies and Applications, Italy : Anzio, Roma, (2013).

2. Al-Masri A., et all, $A 3 D C F D$ model for predicting the temperature distribution in a full scale APU SOFC short stack under transient operating conditions, Germany : Institute of Energy and Climate Research, Electrochemical Process Engineering (IEK-3), (2014).

3. Huang Kevin and Goodenough John B., Solid Oxide Fuel Cell Technology : principle, performance and operations, USA : North America, Woodhead Publishing Limited and CRC Press LLC, (2009).

4. Hedayat Nader, et all, Pyrolyzable pore-formers for the porous-electrode formation in solid oxide fuel cells: A review, USA : College of Aeronautics and Engineering (CAE), Kent State University, Kent, OH 44242, (2017).

5. Wincewicz Keegan C., Cooper Joyce S., Taxonomies of SOFC material and manufacturing alternatives, USA : Design for Environment Laboratory, Department of Mechanical Engineering, University of Washington, Seattle, WA 98195, (2004).

6. Sleiti Ahmad K., Performance of tubular solid oxide fuel cell at reduced temperature and cathode porosity, United States : The William States Lee College of Engineering, UNC Charlotte, 9201 University City Blvd., Charlotte, NC 28223, (2010).

7. Sulistyo, Pengontrolan Kualitas Anode SOFC melalui Pengontrolan Porositas, Indonesia : Jurusan Teknik Mesin, Fakultas Teknik Universitas Diponegoro, Semarang, (2015).

8. Qu Zuopeng, et all, Three-dimensional computational fluid dynamics modeling of anode-supported planar SOFC, The Netherlands : Department of Process \& Energy, Delft University of Technology, (2010).

9. $\mathrm{Qu}$ Zuopeng, et all, Three-dimensional thermo-fluid and electrochemical modeling of anode-supported planar solid oxide fuel cell, The Netherlands : Department of Process \& Energy, Delft University of Technology, (2010).

10. Danilov Valery A., Tade Moses O., A CFD-based model of a planar SOFC for anode flow field design, Australia: Department of Chemical Engineering, Curtin University of Technology, Perth WA 6001, (2009).

11. www.accuratus.com, Accuratus Ceramic Corporation.

12. Shao Q., et all, An advanced numerical model for energy conversion and crack growth predictions in Solid Oxide Fuel Cell units, Luxembourg : Luxembourg Institute of Science and Technology (LIST), 6, Avenue des Hauts-Fourneaux, 4362 EschSur-Alzette, (2015).

13. Fluent, Inc., Tutorial Guide, FLUENT, Inc., (2006).

14. Tuakia, Firman., Dasar-dasar CFD Menggunakan FLUENT, Informatika, (2008). 